\title{
Toward Mitigating Urban Heat Island Effects: Investigating the Thermal-Energy Impact of Bio-Inspired Retro-reflective Building Envelopes in Dense Urban Settings
}

\author{
Yilong Han ${ }^{\mathrm{a}}$, John E. Taylor ${ }^{\mathrm{b}, *}$, Anna Laura Pisello ${ }^{\mathrm{c}}$ \\ ${ }^{a}$ Charles E. Via, Jr. Department of Civil and Environmental Engineering, Virginia Tech, 121 Patton Hall, \\ Blacksburg, VA 24061, USA \\ ${ }^{\mathrm{b}}$ Charles E. Via, Jr. Department of Civil and Environmental Engineering, Virginia Tech, 113B Patton Hall, \\ Blacksburg, VA 24061, USA \\ ${ }^{c}$ Department of Engineering, University of Perugia, Via G. Duranti 93, 06125 Perugia, Italy
}

\begin{abstract}
More than one-third of energy expenditure is attributable to buildings. Urbanization is leading to tighter spatial interrelationships among buildings, which is escalating building energy consumption due to the impact of buildings on one another. This, in turn, is exacerbating Urban Heat Island (UHI) effects. We sought a bio-inspired solution to this significant engineering issue and discovered a similar heat island effect in flowers, namely the "microgreenhouse effect." However, a special cooling effect has been observed in a temperate flower-Galanthus nivalis - which generates cooler intrafloral temperatures. In this paper, we studied the special retro-reflecting property of the flower petals, which has been suggested as a possible contributor to this cooling effect, and modeled a bio-inspired retro-reflective building envelope. We conducted cross-regional energy simulation of building networks in order to examine its thermal-energy impact. We found that building surface temperatures dropped considerably when neighboring buildings were retrofitted with a bio-inspired retro-reflective façade. We concluded that a bio-inspired retro-reflective building envelope can; (1) lessen the reflected heat of solar radiation in spatiallyproximal buildings leading to reduced UHI, and (2) reduce the energy required for cooling. These findings have broad implications for building design, urban planning, development of retro-reflective technology, and environmental conservation.
\end{abstract}

Keywords: Bio-Inspired Design; Building Networks; Energy Conservation; Inter-Building Effect; Mutual Reflection; Urban Heat Island Effect

\footnotetext{
* Corresponding author. Tel.: +1 540231 0972; Fax: +1 5402317532.

E-mail addresses: ylhan@vt.edu (Yilong Han), jet@vt.edu (John E. Taylor), pisello@crbnet.it (Anna Laura Pisello).
} 


\section{Introduction}

Over the last decade, rapidly growing world energy expenditure has raised attention and generated concerns. According to the 2013 Key World Energy Statistics [1], annual global energy consumption has grown from 4000Mtoe (million tonnes of oil equivalent) to nearly 9000Mtoe during the last 40 years (1971-2011). Over the same period, $\mathrm{CO}_{2}$ emissions have doubled. Intensified energy consumption not only causes supply difficulties and exhaustion of fossil energy resources, but also significantly influences the human living environment, triggering global environmental deterioration, including ozone layer depletion, global warming, and climate change [2]. Contributing to these frightening trends, $32 \%$ of total final energy consumption and nearly $40 \%$ of primary energy consumption are attributable to buildings [3]. In the United States, nearly half (47.6\%) of all energy produced, and three-quarters of electricity is consumed by the building sector every year [4]. Thus, how to achieve a more sustainable built environment has become a major task for engineers, building researchers and energy policy makers.

Urbanization is challenging the efforts to achieve a more sustained built environment and has become a central topic in fast-developing countries over the last several decades [5]. A recent United Nations Report indicated that a significant shift in population from rural areas to urban areas would occur and cause pressure on energy, resources and the environment [6]. Population in urban areas is projected to increase by $72 \%$, from 3.6 billion in 2011 to 6.3 billion in 2050. As a result, it is reasonable to expect the morphology of urban areas to involve much tighter spatial interrelationship among buildings that may exacerbate urban environmental issues.

The existence of an urban heat island (UHI) effect has been documented for over a century [7]. UHI refers to a significantly warmer metropolitan area than its surrounding rural area attributed to human activities. Although such urban heat climates can be considered as a mild offset for some temperate, cold, or high-latitude cities in winter [8], the heat effect would be further intensified in summer days, adding discomfort and increasing the airconditioning load. Previous research on UHI suggests that this phenomenon is essentially produced by the dense construction surfaces that absorb solar radiation more than natural surfaces, and the anthropic heat flux due to the cooling and heating of the buildings $[9,10]$. Thus, urbanization would most likely exaggerate the UHI effect, which will not only influence the health and welfare of urban inhabitants, but also exacerbate global energy concerns. Researchers have argued that such consequence is already occurring [5]. Energy usage in China has been growing dramatically along with the economic boom and population migration in urban areas over the last decade, and China replaced the United States as the largest energy consumer in 2010 [11]. Although measures have been investigated 
and developed to mitigate existing UHI effects [9, 12-20], such as increasing urban thermal mass, expanding evaporative surfaces and vegetation covers, choosing high albedo urban paving and roofs for both their active and passive effects etc., the results are not as encouraging as anticipated.

Urban geometry also plays a particular role in establishing building/urban behaviors [21]. It is difficult to predict building energy performance accurately without considering the close proximity of other buildings in the urban environment and energy implications that could result. Recent research has demonstrated that the

interrelationship between buildings within building networks, namely the Inter-Building Effect (IBE), results in inaccuracies of energy consumption predictions (up to $42 \%$ in summer, and up to $22 \%$ in winter) for heating and cooling $[22,23]$. The research also demonstrates that the energy performance of one building can be significantly impacted by surrounding buildings through mutual reflection and mutual shading. Therefore, in order to deal with denser urban building morphology owing to urbanization, we need more research that examines inter-building relationships from the perspective of heat re-radiation in order to mitigate heat flux under a building canopy. Hence, the objective of this research is to explore solutions for reducing Inter-Building Effects that contribute to UHI effects.

\section{Background and Research Objective}

While researchers have been researching solutions for reducing energy consumption in the built environment from engineering or architecture perspectives, it is possible that answers may lay hidden in nature. Nature, through a long period of trial and error, may have already solved many of the problems we are struggling with today. Biomimicry was introduced as an applied science that derives inspiration for solutions to human problems through the study of natural designs, processes and systems [24]. Although widespread and practical application of biomimicry as an architectural design method remains largely unrealized, several biomimicry solutions and optimization methods have already been successfully implemented in building systems [25-28]. Recently, the integration of biomimetics has also emerged in building and energy research in order to achieve a more sustained built environment [29-32]. Two approaches have been developed to utilize biomimicry in engineering and architecture, including a problembased approach and a solution-based approach [33, 34]. Unlike the "biology influencing design" approach that is guided by sophisticated knowledge and background in biology, the problem-based approach allows designers to identify human problems and then examine ways natural organisms have solved similar issues without an a priori indepth biological understanding. 
With our motivation to find a bio-inspired solution for the UHI that occurs in dense urban settings $[27,28$, 35-37], we first discovered several similarities between building systems and botanical systems, in particular flowers, following the problem-based approach [34]. A building envelope is similar to flower petals; the inter-building area enclosed by building envelopes in close proximity is akin to the intrafloral area encircled by petals; building occupants interact in and among buildings, while pollinators forage inside flowers, etc. We were then surprised to realize a similar effect to urban heat islands inside flower petals, the so-called "micro-greenhouse effect" [38] due to warmer intrafloral temperatures than ambient temperature. Flowers and their pollinators derive benefits from warm air $[39,40]$ while the UHI effect is generally considered a negative phenomenon to be mitigated in cities.

Researchers have also discovered several cooling mechanisms, such as evaporation at the expense of water and self-shading by their tepals [41], which have also been evolved in flowers under extreme temperatures and locations. We identified one flower in particular with an adapted cooling mechanism. Galanthus nivalis is a bellshaped "hanging flower" with white oblong flowers of about 2-4 cm in length bending to the ground. Research has shown that hanging flowers seem to be capable of collecting energy with significantly warmer intrafloral temperatures since the hung flowers act as traps for rising warm air from the ground [42]. However, a recent study about temperature distribution in light-colored flowers found that Galanthus nivalis exhibits a peculiar cooling effect [43]. The measurement by infrared cameras showed a uniform temperature which is 2.7 degrees Celsius lower than ambient. Another phenological study in Central Europe also disclosed tendencies toward earlier flowering of Galanthus nivalis [44]. Although no theory yet exists to fully explain Galanthus nivalis' cooling mechanism [43], the special directional reflective property of the flower petals has been suggested as a possible contributor (Fig. 1).

Insert Figure 1 about here

Retro-reflection is a typical optical property that has the concept of directional reflective features, and is generally achieved through multiple reflections within the retro-reflector through subtle surface designs [45], such as spherical lenses (tiny glass beads) and prismatic elements (cube corner). Unlike specular reflection and diffuse reflection that occur in urban environments with conventional building materials, retro-reflection is the property of light rays striking a surface and being redirected back to the light source. Although the visibility properties of retroreflection have been studied, the use of this technology is still limited to specific purposes, e.g. improving pavement 
markings and road signs for safety and illumination [46] and passive solar systems [47]. The thermal impact due to the retro-reflective property is still not clear. Galanthus nivalis may use retro-reflective-like microstructures in the petals to reflect solar radiation out of its micro-floral environment in order to retain a cool intra-floral area and escape the floral heat effect. Different from the non-significant and non-shiny light response by diffusive reflective materials and a single bright spot being observed from specular reflection, this retro-reflective-like optical property of the flower petals is illustrated by the camera flash reflection in Figure 1 where the shiny lighting effect was observed continuously across the curving flower petals. We investigate whether such impact could also be practicable in a larger scale, i.e. at the inter-building level, to potentially mitigate Urban Heat Island effects.

Materials with such optical features have started to draw attention and have been studied as possible solutions for building applications, such as holographic optical elements [48], prism glass panes [49], acrylic diffusers [50], and electrochromic glazing [48]. Recent studies of retro-reflective technology have focused on experimental measurement of retro-reflectance and durability of retro-reflective specimens in miniature models for building applications [51-54]. These studies have led to an increased awareness that building thermal-energy behaviors could be impacted potentially by such directional reflective characteristics. Nevertheless, we lack research on how a retro-reflective surface may impact the surface temperature and energy performance of buildings in dense urban settings. By implementing advanced numerical analysis approaches, this research aims to fill this literature gap by examining whether a retro-reflective building surface plays a role in forming and retaining a cooler intra-area among buildings located in close proximity.

\section{Methodology}

\subsection{Hypotheses}

To answer the research questions inspired by the peculiar thermal and reflective property of Galanthus nivalis, two hypotheses were proposed as follows,

Hypothesis 1: Retro-reflective building envelopes lead to lower surface temperatures in neighboring buildings in an urban context where buildings are in close proximity;

Hypothesis 2: Retro-reflective building envelopes lead to reductions in the energy required for cooling in an urban context where buildings are in close proximity. 


\subsection{Retro-reflective Surface and Simulation Development}

In order to meet the needs of increasing the sustainability and energy efficiency of buildings, building energy analysis and dynamic simulation have developed rapidly over the last several decades, and have become powerful tools for predicting and improving building energy performance both for research and design purposes [55-57]. The first step in our simulation effort was to identify a surface design that could be modeled in an energy simulation environment that enables retro-reflective property investigation. The current application of retro-reflectance is to embed micro-level optical retro-reflectors into material surfaces or plastic sheets to improve visibility. Thus, in order to attain similar and substantial retro-reflectance in an energy simulation environment, we proposed a macro-scale retro-reflective surface design with an array retro-reflector pattern (Fig. 2). Cubic-corner retro-reflectors have acceptance angles of $\pm 50^{\circ}$ [58], and are more effective in sending the light back to the source and recent research [52] has confirmed the advantage of prism-array sheet samples that exhibited a total reflectance of $71.0 \%$ to $77.8 \%$, with $23.5 \%$ to $29.5 \%$ retro-reflectance, more than two times better than that of beam-embedded sheets $(\sim 10 \%)$ in terms of retro-reflective property. Therefore, we designed our retro-reflective pattern façades such that each unit cell of the pattern was a cubic-corner retro-reflector consisting of three mutually perpendicular plane surfaces.

Insert Figure 2 about here

EnergyPlus is an energy analysis and thermal load simulation engine distributed by the U.S. Department of Energy [56]. Over the last decade, EnergyPlus has become a popular research tool for energy performance simulation [22, 23, 59-61], and thus was chosen here for the dynamic analysis. For the authenticity of simulation results, information about construction materials, temperature set points, and schedules for lighting, equipment, and occupants were retained from a case study urban residential block [22], and will be discussed in the following sections. EnergyPlus also has sophisticated functions to model HVAC (Heating, Ventilation and Air Conditioning) systems. For the purpose of studying the HVAC energy consumption of reference buildings without considering the mechanical efficiency, the Ideal Loads Air System setting, an ideal status of HVAC model, was implemented for this study.

Although it uses three-dimensional coordinates to define thermal zones and urban geometries, EnergyPlus itself has limited functionalities to facilitate geometric information inputs. When building envelopes with detailed 
surface patterns are simulated, such as a geometrically complex retro-reflective façade design, EnergyPlus not only requires extensive input data and a prohibitively long running time, but also can result in error-prone analysis. To overcome this limitation, we implemented OpenStudio, a graphical third-party application developed by the National Renewable Energy Laboratory (NREL) to support whole building energy modeling, to visualize and build a precise model in a SketchUp interface. This allowed for geometric coordinate extraction for EnergyPlus input. In addition, shading surfaces, an essential geometric element of EnergyPlus for shading and reflection [62], were extensively used to model testing surfaces and nearby building envelopes to reduce required computational power.

Numerical urban thermal information is essential in investigating the UHI phenomenon. However, EnergyPlus does not simulate the effects of the urban morphology and environment on local air thermal behavior [62] since the meteorological information such as wind speed, wind direction, and air temperature are directly read from pre-defined weather files. The EnergyPlus simulation environment uses a ray-tracing method to calculate solar radiation that is diffusely reflected onto each of a building's exterior surfaces, namely "receiving surfaces" [62]. By generating a set of rays proceeding into the outward hemisphere at each receiving point, it determines whether each ray hits the sky, ground, or an obstruction. The radiance at the hit point from the reflection of an incident beam or sky solar is determined and the contribution of this radiance to the receiving surface is calculated, added to the contribution from other hit points, and averaged over the receiving points. Thus, the amount of reflected solar radiation could be estimated by monitoring variations of surface temperatures, which is a proxy for changes in urban thermal behavior. In order to evaluate and quantify how the proposed retro-reflective property could impact thermal and energy assessments, two case studies were designed to represent the inter-building context. The proposed procedure began with a reference building with a neighboring testing surface in the first case study, followed by year-round simulation of a network of buildings subject to different climatological contexts in the second case study. For each case, a regular plane diffusive wall and a retro-reflective pattern diffusive wall were applied to building exterior façades for separate simulation runs. Thus, the solar radiation gain by the wall surface of the control building would be represented differently due to the varying incident, reflected and absorbed solar radiation in different scenarios. Based on the comparison of results, it is possible to measure the magnitude of thermal and energy behavior differences. 
Insert Figure 3 about here

\subsection{Case Study 1: Examining Surface Temperature}

The first case study is illustrated in Figure 3, which consisted of a stand-alone reference building and a neighboring testing surface on the west side. The reference building (on the right) was modeled as a three-story building with a square shape of 10 meters per side, while the testing surface (on the left) was represented using a shading surface element in EnergyPlus. The testing surface acted as a neighboring building's exterior wall. The distance between the testing surface and the reference building is 6 meters. Inherited from a previous IBE case study urban block [22], the opaque envelope of the reference building consists of external brickwork $(0.10 \mathrm{~m})$, XPS extruded polystyrene $(0.080 \mathrm{~m})$, lightweight concrete block $(0.010 \mathrm{~m})$, and internal gypsum plasterboard $(0.013 \mathrm{~m})$, with a global thermal transmittance of $0.314 \mathrm{~W} / \mathrm{m}^{2} \mathrm{~K}$. The roof contains an internal layer of plasterboard $(0.015 \mathrm{~m})$, an air gap and roof structure $(0.20 \mathrm{~m})$, glass wool insulation $(0.15 \mathrm{~m})$ and asphalt $(0.010 \mathrm{~m})$, and it represents a global thermal transmittance of $0.250 \mathrm{~W} / \mathrm{m}^{2} \mathrm{~K}$. The internal ceiling consists of gypsum plasterboard $(0.015 \mathrm{~m})$, lightweight cast concrete $(0.10 \mathrm{~m})$, elastomeric foam $(0.005 \mathrm{~m})$, and lightweight plywood $(0.020 \mathrm{~m})$. The ground floor includes wooden flooring $(0.020 \mathrm{~m})$, mineral wool $(0.15 \mathrm{~m})$, floor structure $(0.20 \mathrm{~m})$, and external rendering $(0.025 \mathrm{~m})$, and it represents a global transmittance of $0.246 \mathrm{~W} / \mathrm{m}^{2} \mathrm{~K}$. The external windows are modeled as double clear glass panes (6mm-6mm with $6 \mathrm{~mm}$ air). The diffuse solar reflectance of the exterior vertical façades is $40 \%$ according to the inherited building models. The east façades of the reference building, opposing to the testing surface, worked as a control surface for the analysis and monitoring process. Figure 4 provides several examples of azimuths of the sun, how the shadows were cast, and how the solar beams were reflected over the course of the simulation. Since the testing surface faced toward the east, the re-directed solar reflection from the shading surface to control surface was analyzed primarily in the morning due to the projection of sunlight. The top and right parts of the testing surface were sunlit in early morning around 7 a.m.; later at 9 a.m., only the bottom part was not directly hit by solar beams; the entire surface was receiving and reflecting solar radiation two hours later. Since surface temperatures were influenced by the amount of solar radiation that was being received, this comparative analysis could be conducted 
correspondingly by studying the temperature variations of the control surface at different times to test the first hypothesis.

Insert Figure 4 about here

In addition to the analysis of temperature differences at specific times, all-day average temperature variations of the control surface were also conducted under two different climatological contexts, Minneapolis, Minnesota and Miami, Florida, as they are the coldest and hottest cities in the United States in terms of average annual temperatures representing two extreme climate conditions. Four typical seasonal dates, January $21^{\text {st }}$ (typical winter day), April $21^{\text {st }}$ (typical spring day), July $21^{\text {st }}$ (typical summer day), and October $21^{\text {st }}$ (typical fall day) were selected to calculate the average value of temperature variation of the control surface in Minneapolis and Miami, respectively. All-day average temperatures were calculated during the daytime (from sunrise to sunset) for each situation when the sunlight could impact the mutual interaction between neighboring buildings.

\subsection{Case Study 2: Examining Primary Energy for Heating and Cooling in Realistic Urban Contexts}

Unlike the first case study that focused on the examination of dynamic thermal impact of a retro-reflective façade, the second case scenario was aimed at understanding how the energy behavior of the HVAC systems of a building could be influenced when a retro-reflective surface was applied on building envelopes of an entire building network. To test that, we developed a nine-building block within the EnergyPlus modeling environment as shown in Figure 5. The control building was situated in the center of the block, surrounded by eight shading-surface buildings. The morphology of each building was the same for all buildings within the network. The distant between buildings was set to be 6 meters $($ Height/Width ratio $=1.5)$ in the East-West direction and 3 meters $($ Height/Width ratio $=3)$ in the North-South direction. Only adjacent building envelopes that could potentially influence the control building were modelled using retro-reflective façades. In the EnergyPlus simulation environment, secondary reflections are not considered. In other words, solar radiation directed from the control building to the ambient would never return through secondary reflections of its neighboring obstructions in this numerical analysis environment. Thus, to reduce modeling and computational difficulties of thermal zones, the control building surface reflectance was set as 
75\%. This value was set based on a related study [52], which found that the reflectance in a prism-array retroreflective sheet is around $71.0 \% \sim 77.8 \%$.

Insert Figure 5 about here

In order to quantify and systematically analyze the retro-reflective effect especially in urban context, the building network simulation was carried out with respect to different real climate conditions. Eight populous cities were selected covering four U.S. census regions (Northeast, Midwest, South, West) and six climate zones as follows [59, 63, 4: West Region - Los Angeles, CA (zone 2) and San Francisco, CA (zone 3); Midwest Region - Chicago, IL (zone 5) and Minneapolis, MN (zone 6); Northeast Region - New York, NY (zone 4) and Boston, MA (zone 5); and South Region - Houston, TX (zone 2) and Miami, FL (zone 1). The selected cities are ranked within the top 50 cities in the United States by population and are located in the top 20 metropolitan areas reported by the U.S. Census Bureau. They covered zones 1-6 of the eight climate zones defined by International Energy Conservation Code where zone 7 and 8 represent the coldest areas in the United States with no populous cities. Sixteen more simulations were run in the second case study for the cross-regional analysis. Monthly and annual energy consumption of each individual city were compared regarding heating energy, cooling energy, and total energy consumption of HVAC.

\section{Analysis and Results}

\subsection{Case Study 1: Impact on Surface Temperatures}

In the first cast study, a 15-day period (June $1^{\text {st }}-$ June $15^{\text {th }}$ ) was simulated for the initial investigation of the dynamic thermal comparing diffusive to retro-reflective surfaces. Weather data from Miami was input. As a warmer city, we expected it to yield more pronounced outcomes. The control surface of the reference building was broken down into three sections (top, middle, and bottom) and 24 parts for local thermal analysis as marked in Figure 6. The average temperature of each sub-surface was calculated, and the simulation result of the temperature difference is contained in Figure 7 at three different times in the morning ( 7 a.m., 9 a.m., and 11 a.m.) when solar light could be reflected to the control surface by the testing surface through mutual reflection. In Figure 8, the solid black histograms represented the temperatures of the control surface when a regular diffusive wall was used as the testing surface; 
while the white histogram bars registered the temperature of a control surface under the retro-reflective context. Although thermal distribution patterns vary in different scenarios, we observed in all instances that temperatures of the control surface dropped considerably.

Insert Figure 6 about here

Insert Figure 7 about here

In order to better understand this thermal phenomenon, the control building surface was further divided into $324(18 \times 18)$ area-equal sub-areas (data points) for higher resolution local comparison and better visualization. The graph in Figure 8 illustrates temperature difference distribution maps which indicate the impact of the retroreflective property on the thermal behavior of building façades. The lighter parts in Figure 8 represent that no significant thermal variances occurred for different testing surfaces, while the darker shaded parts represent that a considerable reduction of temperature occurs when the testing surface was retrofitted with a retro-reflective façade. At 7 a.m., there was little temperature difference at the bottom right part of the control surface, while the top left part started to exhibit a cooling effect. As the sun height rose and more solar beams reached the testing surface, the cool area expanded and moved downwards in the distribution map. This trend is due to the fact that the dynamic thermal behavior of the control building is closely related to the incident angle of solar beams, as the reflected light by the testing surfaces would heat the control surface. The average decrease in temperature of the entire surface was 0.43 degree Celsius, 0.85 degree Celsius, and 0.99 degree Celsius at 7 a.m., 9 a.m. and 11 a.m., respectively. The maximum temperature differences were up to 0.66 degree Celsius at 7 a.m., 1.39 degree Celsius at 9 a.m., and 1.64 degree Celsius at 11 a.m.

Insert Figure 8 about here

Table 1 shows the results of average temperature reductions of the control building surface during daytime at typical seasonal days in Miami and Minneapolis. In both of the two cities, summer days register the highest 
temperature reductions owing to the longer daylight time and the steeper sunlight angles while typical winter days result in the lowest simulated surface temperature reductions. This observation is further supported by closer inspection of the values for each separate location. Miami has a long summer and a mild winter such that the average reduction of the typical winter day does not differ substantially from the other seasonal days. On the other hand, Minneapolis is characterized by a long, cold winter and a hot, humid summer which is reflected by the more marked differences between winter and summer surface temperatures. It is worth noting that in this simulation we only considered one side of the reference building, the testing surface only played a significant role in roughly half of the daylight hours in affecting the control building surface. For this reason, the all-day average values in Table 1 are not as large as the results of specific times presented earlier in this section.

Insert Table 1 about here

\subsection{Case Study 2: Impact on Primary Energy for Heating and Cooling}

In order to describe the potential impact of the retro-reflective property on energy behavior, the second case study was carried out in the context of an urban block. Climatological information of Miami, FL and Minneapolis, MN was also used to first conduct year-round simulation since these two cities represent the extreme climate condition in the United Stated where heating and cooling loads are concerned. Since Miami, FL does not have distinct four seasons and Minneapolis, MN has a relatively long cold winter, the monthly simulated results are used here instead of more compact seasonal values, as shown in Table 2 with respect to heating energy and cooling energy consumption by the HVAC systems of the control building. We observed a decrease in cooling loads under hot climates; however, heating consumption was detected to increase somewhat in cold seasons due to less re-directed solar radiation being absorbed by building exterior walls.

Insert Table 2 about here

We then expanded to a cross-regional energy analysis of eight cities. Table 3 includes the results of this analysis. Cooling energy and total energy reductions were calculated specifically in terms of both absolute values (in 
the unit of kilowatt-hour $(\mathrm{kWh})$ ) and relative percentage $(\%)$. For each category, the largest observed values are highlighted in bold. From the table we can observe that the cooling energy demand percentage varied from $36 \%$ in Minneapolis, MN to almost 100\% in Miami, FL of total HVAC energy. As a whole, we found that the total energy consumption and cooling energy consumption were reduced by up to $8.2 \%$ and $9.8 \%$, respectively, in different metropolitan areas.

Insert Table 3 about here

Los Angeles, CA, Miami, FL, and Houston, TX were the three cities that had the highest values for both cooling energy savings and total energy savings, where more than $96 \%$ of energy contributed to the cooling requirement. San Francisco, CA also had a much higher cooling demand (93\%) compared to heating, achieving a $9.83 \%$ reduction in cooling consumption and $8.22 \%$ in total HVAC energy consumption. Although the other four cities from cooler climate zones in the Midwest and Northeast did not amount to the improvements of the aforementioned four cities, we still observed reductions in energy consumption for each.

\section{Discussion}

A great deal of research effort has focused on reducing energy consumption in the built environment due in part to the fact that nearly $40 \%$ of primary energy consumption are attributable to buildings and the fact that urban sprawl and population migration are exacerbating energy concerns $[3,6]$. Previous research has identified that building energy performance is influenced by Inter-Building Effects especially in buildings that are in close proximity to each other $[22,23]$, i.e. through shading and reflection, which also contribute UHI effects that have a negative impact on urban thermal-energy behavior. The research presented in this paper contributes to this discussion through a bio-inspired endeavor $[34,65]$. Driven by the advantages of nature's time-tested patterns and solutions that may be implemented in the context of the built environment, the authors identified a directional reflective property from retro-reflective flower petals which exhibit a cooling effect [43], and analyzed the thermal and heat-transferring characteristics under the building network context in a dynamic simulation environment.

This paper contributes a perspective on how a retro-reflective building surface influences the thermal performance of neighboring building envelopes. Based on previous literature that retro-reflectors could direct the 
solar rays back to the source [46, 52], we expected that less solar radiation would reach the control surface opposing the retro-reflective façade. We designed a case study of a simple one-surface-one-building scenario to examine our first hypothesis. The construction materials and thermal characteristics remained the same to govern the comparative simulation, while the testing surface was modelled with either a diffusive wall or the retro-reflective array pattern. Temperatures were measured and monitored in the control surface. The results in Figure 7 and Table 1 reveal consistent trends of lower surface temperatures of the control building over the course of the simulation period when the testing surface was retrofitted with a retro-reflective façade. Thus we found support for our first hypothesis. Since identical diffusive solar radiation by the sky would reach the control surface under the same simulated weather environment, we are confident to conclude that less solar radiation has reached the control building owing to the change of the surface design. Figure 8 illustrates how the retro-reflective façade contributes to cooling during the daytime. The cooler part shifts accordingly to the location and height of the sun, which improves the ability of the directional reflective building envelopes to shift the reflected solar radiation outside the urban canopy.

This paper also contributes a systematic approach to examine retro-reflective building envelopes on building cooling and heating energy performance. Consistent with retro-reflective thermal characteristics in the first case study, less heated building surfaces were expected to lead to reduced cooling energy consumption. As an extension of the investigation of the Inter-Building Effect [22, 23], a second case study was developed as a network of buildings scenario incorporating different real climatological input and realistic local environmental conditions to explore our second hypothesis in terms of building energy behavior. We investigated eight populous cities covering all four Census Regions in the United States and the cross-regional results confirm reductions in building cooling energy over six major climate zones. This outcome is due to mitigated mutual reflection that can negatively impact cooling energy consumption in dense urban settings. However, mutual reflection could also be considered as a mild offset in winter to lessen the heating demand, which is reflected in the simulated results from northern areas which resulted in considerable cooling energy conservation but less HVAC energy savings. Taken as a whole, we found support for Hypothesis 2 as energy use reductions were observed in all cities and all regions simulated. This second case study offers a better understanding of the reflection component of the Inter-Building Effect. It also suggests that retro-reflective building envelopes might have more impact in warmer climatic cities that have longer daylight time and more demand for cooling energy. 
The main contribution of this research is the exploration of the directional reflective property on urban thermal dynamics. Highly reflective materials have been studied for possible use as cool roof materials to mitigate UHI effects [17, 66, 67], but high albedo was not advisable on exterior walls because the reflected solar radiation from them would be absorbed by the surroundings. Computer-controlled building panels have also been implemented that could manipulate solar directions by rotating the angle of mirrors to reduce the cooling demanding [68]. However, the mechanical systems of movable panels are complicated to design and build, consume energy, and are costly and time-consuming to maintain. In contrast, retro-reflective building envelopes could enable similar functionality of directional reflection without having any moving parts, thus requiring little maintenance effort. Although current measures of retro-reflective techniques are limited to specific purposes [46], they have been well studied and widely used, which may facilitate implementation in the built environment. Since research has already suggested that UHI effects are largely produced due to the fact that more solar radiation is absorbed by construction surfaces than natural surfaces $[9,10]$, the retro-reflective property could extend the conception of "cool roofs" to vertical urban envelopes [52,69], i.e. "cool walls", in mitigating UHI effects. As a result, counterbalanced heat effects would foster a comfortable urban living environment reducing negatively impacted mutual reflection in urban areas, and mitigating cooling demands in the built environment.

The purpose of this research was to examine whether retro-reflectance contributes a cooling effect, potentially mitigating UHI effects. The result of the thermal and energy behavior of building networks in this research provide support that UHI effects may be mitigated. A human-based check was conducted to ensure the accuracy of the dynamic simulation result. No exception output or process warnings were observed over the course of the simulation. Nevertheless, the modeling and simulation efforts also result in some limitations. Although the simulation model was built upon previous IBE research that had been validated by empirical data, the network of buildings modeled only included nine buildings for this preliminary study to keep the research scope reasonable but sufficiently detailed to examine the proposed research questions. It is possible that larger urban-scale phenomena of retro-reflective surfaces may exist and, if so, were neglected in this research. Empirical analysis will also be implemented to support and further calibrate the simulation models in future research. Given that IBE and UHI effects are likely to be more substantial in a central city area where tall buildings interact with a spatially proximal building network, the simulated block size, morphology and urban layout should also be considered for a more throughout parametric analysis in future research. Rather than studying the balance between heat/radiation entering 
and leaving the wall surface, this research focused on the thermal temperature impact by this directional reflective feature. Future research will include radiative and heat budget studies for a more in-depth understanding of such an optical response, especially in larger scale investigations. Another limitation is within the simulation environment itself. Even though EnergyPlus provides a well-developed simulation platform for researchers, it does not support the calculations of secondary reflection which would minimally impact the results. As the simulation tools evolve, these secondary effects should be examined and quantified. Also, notwithstanding the fact that our research hypotheses were built upon optical and biological understandings, we still have limited knowledge on the peculiar intra-floral cooling effect that could be fully implemented in the built environment. Comprehensive thermal and optical analyses have been included for a more thorough interpretation of such phenomena in future research plans.

\section{Conclusions}

In this paper, a method for evaluating the thermal and energy performance of urban building networks from a retroreflective perspective was proposed and described. The concept was inspired by Galanthus nivalis petals that enable it to escape a similar heat effect as UHI effects in floral world [43]. The research built upon previous approaches that studied the thermal and energy dynamics of inter-building relationships, utilizing the same urban block models to facilitate comparison $[22,23]$. Two case studies were established and simulated in dynamic simulation environment for thermal-energy building assessments. Temperature variations and the dynamic thermal behavior of the control surface in the reference building were first analyzed with a proposed cubic-corner retro-reflective design façade applied to its neighboring building's exterior envelope. The second case study then expanded to a nine building urban block for a systematic cross-regional analysis of building energy performance. The building block was studied in eight different populous metropolitan areas, covering all four census regions and six major climate zones in the United States. The findings of temperature difference distribution demonstrate that building surface temperatures dropped consistently and considerably when neighboring buildings were retrofitted with a retro-reflective façade. Moreover, the results revealed reductions of cooling energy consumption under the retro-reflective context for both total energy consumption and cooling energy consumption of HVAC, by up to $8.2 \%$ and $9.8 \%$ in different metropolitan areas. These thermal and energy behavior results could play an important role in mitigating UHI effects. This will become increasingly important in the future as buildings in urban areas evolve into tighter spatial relationships triggered by population migration and urbanization. 


\section{Acknowledgements}

This material is based in part upon work supported by the National Science Foundation under Grant No. 1142379 and by the BioBuild Virginia Tech Interdisciplinary Graduate Education Program grant. Any opinions, findings, and conclusions or recommendations expressed in this material are those of the authors and do not necessarily reflect the view of the National Science Foundation or the BioBuild Interdisciplinary Graduate Education Program. The authors' acknowledgments are due to $\mathrm{H} 2 \mathrm{CU}$ (Honors Center of Italian Universities) for supporting the international cooperation among the authors. The third author acknowledgments are also due to the "CIRIAF program for UNESCO" in the framework of the UNESCO Chair "Water Resources Management and Culture", for supporting her research.

\section{References}

[1] International Energy Agency. Key World Energy Statistic; 2013. 〈http://www.iea.org/publications/freepublications/publication/KeyWorld2013.pdf $>$.

[2] L. Perez-Lombard, J. Ortiz, C. Pout, A review on buildings energy consumption information, Energy and Buildings 40 (3) (2008) 394-398.

[3] International Energy Agency. Energy Efficiency. 〈http://www.iea.org/aboutus/faqs/energyefficiency〉.

[4] Architecture2030. Architecture 2030 Will Change the Way You Look at Buildings. 2013.

<http://architecture2030.org/the_problem/buildings_problem_why>.

[5] B. Li, R. Yao, Urbanisation and its impact on building energy consumption and efficiency in China, Renewable Energy 34 (9) (2009) 1994-1998.

[6] United Nations, Department of Economic and Social Affairs. World Urbanization Prospects, the 2011 Revision. <http://esa.un.org/unup/>.

[7] L. Howard, The climate of London: deduced from meteorological observations made in the metropolis and at various places around it, Harvey and Darton, London, 1833.

[8] H. Akbari, M. Pomerantz, H. Taha, Cool surfaces and shade trees to reduce energy use and improve air quality in urban areas, Solar Energy 70 (3) (2001) 295-310.

[9] A.M. Rizwan, L.Y. Dennis, C. Liu, A review on the generation, determination and mitigation of Urban Heat Island, Journal of Environmental Sciences, 20 (1) (2008) 120-128.

[10] T. Oke, G. Johnson, D. Steyn, I. Watson, Simulation of surface urban heat islands under 'ideal' conditions at night Part 2: Diagnosis of causation, Boundary-Layer Meteorology 56 (4) (1991) 339-358.

[11] U.S. Department of Energy. Building Energy Data Book; 2011. 〈http://buildingsdatabook.eren.doe.gov〉. 
[12] Y. Huang, H. Akbari, H. Taha, A. Rosenfeld, The potential of vegetation in reducing summer cooling loads in residential buildings, Journal of Applied Meteorology, 26 (1987) 1103-1116.

[13] A.H. Rosenfeld, H. Akbari, S. Bretz, B.L. Fishman, D.M. Kurn, D. Sailor, H. Taha, Mitigation of urban heat islands: materials, utility programs, updates, Energy and Buildings 22 (3) (1995) 255-265.

[14] Y. Kikegawa, Y. Genchi, H. Kondo, K. Hanaki, Impacts of city-block-scale countermeasures against urban heat-island phenomena upon a building's energy-consumption for air-conditioning, Applied Energy 83 (6) (2006) 649-668.

[15] A.L. Pisello, M. Santamouris, F. Cotana, Active cool roof effect: impact of cool roofs on cooling system efficiency, Advances in Building Energy Research, 7 (2) (2013) 209-221.

[16] A.L. Pisello, F. Rossi, F. Cotana, Summer and Winter Effect of Innovative Cool Roof Tiles on the Dynamic Thermal Behavior of Buildings, Energies, 7 (4) (2014) 2343-2361.

[17] E. Bozonnet, M. Doya, F. Allard, Cool roofs impact on building thermal response: A French case study, Energy and Buildings 43 (11) (2011) 3006-3012.

[18] M. Doya, E. Bozonnet, F. Allard, Experimental measurement of cool facades' performance in a dense urban environment, Energy and Buildings 55 (0) (2012) 42-50.

[19] N.H. Wong, C. Yu, Study of green areas and urban heat island in a tropical city, Habitat International, 29 (3) (2005) 547-558.

[20] A. Niachou, K. Papakonstantinou, M. Santamouris, A. Tsangrassoulis, G. Mihalakakou, Analysis of the green roof thermal properties and investigation of its energy performance, Energy and Buildings 33 (7) (2001) 719-729. [21] Z.M.A Chong, N.H. Wong, M. Ignatius, S.K. Jusuf, Predicting the envelope performance of commercial office buildings in Singapore, Energy and Buildings, 66 (0) (2013) 66-76.

[22] A.L. Pisello, J.E. Taylor, X. Xu, F. Cotana, Inter-building effect: Simulating the impact of a network of buildings on the accuracy of building energy performance predictions, Building and Environment, 58 (0) (2012) 3745.

[23] A.L. Pisello, V.L. Castaldo, J.E. Taylor, F. Cotana, Expanding Inter-Building Effect modeling to examine primary energy for lighting, Energy and Buildings 76 (0) (2014) 513-523.

[24] B. Bhushan, Biomimetics: lessons from nature-an overview, Philosophical Transactions of the Royal Society A: Mathematical, Physical and Engineering Sciences, 367 (1893) (2009) 1445-1486.

[25] A. Solga, Z. Cerman, B.F. Striffler, M. Spaeth, W. Barthlott, The dream of staying clean: Lotus and biomimetic surfaces, Bioinspiration \& Biomimetics 2 (4) (2007) S126.

[26] J.S. Turner, R.C. Soar, Beyond biomimicry: What termites can tell us about realizing the living building, in: Proceedings of 1st International Conference on. Industrialised, Integrated, Intelligent Construction, 2008, pp. 221237.

[27] C. Ye, M. Li, J. Hu, Q. Cheng, L. Jiang, Y. Song, Highly reflective superhydrophobic white coating inspired by poplar leaf hairs toward an effective "cool roof”, Energy \& Environmental Science 4 (9) (2011) 3364-3367.

[28] F. Pacheco-Torgal, Introduction to Biotechnologies and Biomimetics for Civil Engineering, in: Biotechnologies and Biomimetics for Civil Engineering, Springer, 2015, pp. 1-19. 
[29] R. Crawford, A.K. da Silva, Experimental testing of a passive, evaporation-based roof cooling system, Energy and Buildings 71 (0) (2014) 12-19.

[30] M.S. Todorovic, J.T. Kim, Beyond the science and art of the healthy buildings daylighting dynamic control's performance prediction and validation, Energy and Buildings 46 (0) (2012) 159-166.

[31] S. Reddi, A.K. Jain, H.-B. Yun, L.N. Reddi, Biomimetics of stabilized earth construction: Challenges and opportunities, Energy and Buildings 55 (0) (2012) 452-458.

[32] G. John, D. Clements-Croome, G. Jeronimidis, Sustainable building solutions: a review of lessons from the natural world, Building and Environment, 40 (3) (2005) 319-328.

[33] S. Yurtkuran, G. Kırl, Y. Taneli, Learning from Nature: Biomimetic Design in Architectural Education, Procedia-Social and Behavioral Sciences, 89 (2013) 633-639.

[34] M.P. Zari, Biomimetic approaches to architectural design for increased sustainability, School of architecture, Victoria University, NZ, (2007).

[35] M.P. Zari, Biomimetic design for climate change adaptation and mitigation, Architectural Science Review, 53

(2) (2010) 172-183.

[36] R.C.G.M. Loonen, Bio-inspired Adaptive Building Skins, in: F. Pacheco Torgal, J.A. Labrincha, M.V.

Diamanti, C.P. Yu, H.K. Lee (Eds.) Biotechnologies and Biomimetics for Civil Engineering, Springer International Publishing, 2015, pp. 115-134.

[37] A. Gamage, R. Hyde, A model based on Biomimicry to enhance ecologically sustainable design, Architectural Science Review, 55 (3) (2012) 224-235.

[38] S.A. Corbet, Pollination and the weather, Israel Journal of Botany, 39 (1-2) (1990) 13-30.

[39] J. Walker, Warm flowers, happy pollinators, Biologist, 54 (3) (2007) 154.

[40] S.A. Rands, H.M. Whitney, Floral temperature and optimal foraging: is heat a feasible floral reward for pollinators?, PLoS One, 3 (4) (2008) e2007.

[41] S. Patino, J. Grace, The cooling of convolvulaceous flowers in a tropical environment, Plant, Cell \& Environment, 25 (1) (2002) 41-51.

[42] J. Mckee, A. Richards, Effect of flower structure and flower colour on intrafloral warming and pollen germination and pollen-tube growth in winter flowering Crocus L.(Iridaceae), Botanical journal of the Linnean Society, 128 (4) (1998) 369-384.

[43] A. Rejšková, J. Brom, J. Pokorný, J. Korečko, Temperature distribution in light-coloured flowers and inflorescences of early spring temperate species measured by Infrared camera, Flora-Morphology, Distribution, Functional Ecology of Plants, 205 (4) (2010) 282-289.

[44] T. Roetzer, M. Wittenzeller, H. Haeckel, J. Nekovar, Phenology in central Europe-differences and trends of spring phenophases in urban and rural areas, International Journal of Biometeorology 44 (2) (2000) 60-66.

[45] H. Eckhardt, Simple model of corner reflector phenomena, Applied Optics 10 (7) (1971) 1559-1566.

[46] R.B. Nilsen, X.J. Lu, Retroreflection technology, in: European Symposium on Optics and Photonics for Defence and Security, International Society for Optics and Photonics, 2004, pp. 47-60. 
[47] H. Köster, Dynamic daylighting architecture: basics, systems, projects, Springer Science \& Business Media, 2004.

[48] A.S. Bahaj, P.A.B. James, M.F. Jentsch, Potential of emerging glazing technologies for highly glazed buildings in hot arid climates, Energy and Buildings 40 (5) (2008) 720-731.

[49] W. Lorenz, Design guidelines for a glazing with a seasonally dependent solar transmittance, Solar Energy 63 (2) (1998) 79-96.

[50] J.T. Kim, G. Kim, Overview and new developments in optical daylighting systems for building a healthy indoor environment, Building and Environment, 45 (2) (2010) 256-269.

[51] J. Yuan, K. Emura, C. Farnham, A method to measure retro-reflectance and durability of retro-reflective materials for building outer walls, Journal of Building Physics (2014) 1744259113517208.

[52] H. Sakai, K. Emura, N. Igawa, H. Iyota, Reduction of reflected heat of the sun by retroreflective materials, Journal of Heat Island Institute International Vol, 7 (2012) 2.

[53] F. Rossi, A.L. Pisello, A. Nicolini, M. Filipponi, M. Palombo, Analysis of retro-reflective surfaces for urban heat island mitigation: A new analytical model, Applied Energy 114 (2014) 621-631.

[54] E. Bonamente, F. Rossi, V. Coccia, A.L. Pisello, A. Nicolini, B. Castellani, F. Cotana, M. Filipponi, E. Morini, M. Santamouris, An energy-balanced analytic model for urban heat canyons: comparison with experimental data, Advances in Building Energy Research, 7 (2) (2013) 222-234.

[55] D.B. Crawley, J.W. Hand, M. Kummert, B.T. Griffith, Contrasting the capabilities of building energy performance simulation programs, Building and Environment, 43 (4) (2008) 661-673.

[56] D.B. Crawley, L.K. Lawrie, F.C. Winkelmann, W.F. Buhl, Y.J. Huang, C.O. Pedersen, R.K. Strand, R.J. Liesen, D.E. Fisher, M.J. Witte, EnergyPlus: creating a new-generation building energy simulation program, Energy and Buildings 33 (4) (2001) 319-331.

[57] S. Heiple, D.J. Sailor, Using building energy simulation and geospatial modeling techniques to determine high resolution building sector energy consumption profiles, Energy and Buildings 40 (8) (2008) 1426-1436.

[58] B. Yang, H. Friedsam, Ray-tracing studies for a whole-viewing-angle retroreflector, Argonne National Lab., IL, United States. US Department of Energy, 2000.

[59] X. Xu, P.J. Culligan, J.E. Taylor, Energy Saving Alignment Strategy: Achieving energy efficiency in urban buildings by matching occupant temperature preferences with a building's indoor thermal environment, Applied Energy 123 (0) (2014) 209-219.

[60] P.G. Ellis, P.A. Torcellini, Simulating tall buildings using EnergyPlus, in: International IBPSA Conference, 2005, pp. 279-286.

[61] A. Scherba, D.J. Sailor, T.N. Rosenstiel, C.C. Wamser, Modeling impacts of roof reflectivity, integrated photovoltaic panels and green roof systems on sensible heat flux into the urban environment, Building and Environment, 46 (12) (2011) 2542-2551.

[62] U.S. Department of Energy. EnergyPlus engineering reference: the reference to EnergyPlus calculations. 2013.

[63] U.S. Census Bureau; 2011. 〈http://www.census.gov/geo/maps-data/maps/pdfs/reference/us_regdiv.pdf> .

[64] International Energy Conservation Code. 2012. 〈https://law.resource.org/pub/us/code/ibr/icc.iecc.2012.pdf>. 
[65] J.M. Benyus, Biomimicry, HarperCollins, 2009.

[66] A. Synnefa, M. Santamouris, H. Akbari, Estimating the effect of using cool coatings on energy loads and thermal comfort in residential buildings in various climatic conditions, Energy and Buildings 39 (11) (2007) 11671174.

[67] A. Synnefa, M. Santamouris, I. Livada, A study of the thermal performance of reflective coatings for the urban environment, Solar Energy 80 (8) (2006) 968-981.

[68] R.L. Reid, A Shade of Distinction, Civil Engineering-ASCE, 83 (12) (2013) 52-57.

[69] H. Akbari, R. Levinson, Evolution of cool-roof standards in the US, Advances in building energy research, 2 (1) (2008) 1-32. 


\section{Table(s) with Caption(s)}

Table 1

Average temperature reductions of the control building surface during daytime at different typical seasonal days in Miami, FL and Minneapolis, MN (in degrees Celsius)

\begin{tabular}{c|c|c|c|c}
\hline City & $\begin{array}{c}\text { Typical Seasonal } \\
\text { Day (Winter) } \\
\text { January 21st }\end{array}$ & $\begin{array}{c}\text { Typical Seasonal } \\
\text { Day (Spring) } \\
\text { April 21st }\end{array}$ & $\begin{array}{c}\text { Typical Seasonal } \\
\text { Day (Summer) } \\
\text { July 21st }\end{array}$ & $\begin{array}{c}\text { Typical Seasonal } \\
\text { Day (Fall) } \\
\text { October 21st }\end{array}$ \\
\hline Miami & 0.32 & 0.40 & 0.46 & 0.37 \\
Minneapolis & 0.12 & 0.40 & 0.42 & 0.22 \\
\hline
\end{tabular}


Table 2

Monthly HVAC energy consumption in Miami, FL and Minneapolis, MN

\begin{tabular}{|c|c|c|c|c|c|c|c|c|}
\hline & \multicolumn{4}{|c|}{ Miami } & \multicolumn{4}{|c|}{ Minneapolis } \\
\hline Month & $\begin{array}{c}\text { Heating } \\
\text { Energy } \\
(\mathrm{kWh})\end{array}$ & $\begin{array}{c}\text { Cooling } \\
\text { Energy } \\
(\mathrm{kWh})\end{array}$ & $\begin{array}{l}\text { Heating } \\
\text { Energy } \\
\text { with } \\
\text { Retro- } \\
\text { reflective } \\
\text { Façades } \\
(\mathrm{kWh}) \\
\end{array}$ & $\begin{array}{l}\text { Cooling } \\
\text { Energy } \\
\text { with } \\
\text { Retro- } \\
\text { reflective } \\
\text { Façades } \\
(\mathrm{kWh})\end{array}$ & $\begin{array}{c}\text { Heating } \\
\text { Energy } \\
(\mathrm{kWh})\end{array}$ & $\begin{array}{l}\text { Cooling } \\
\text { Energy } \\
(\mathrm{kWh})\end{array}$ & $\begin{array}{l}\text { Heating } \\
\text { Energy } \\
\text { with } \\
\text { Retro- } \\
\text { reflective } \\
\text { Façades } \\
\text { (kWh) }\end{array}$ & $\begin{array}{c}\text { Cooling } \\
\text { Energy } \\
\text { with } \\
\text { Retro- } \\
\text { reflective } \\
\text { Façades } \\
(\mathrm{kWh}) \\
\end{array}$ \\
\hline Jan. & 0.0 & 1418.1 & 0.1 & 1335.5 & 4924.6 & 0.0 & 4973.9 & 0.0 \\
\hline Feb. & 1.8 & 1550.8 & 2.1 & 1465.4 & 2838.5 & 0.0 & 2904.1 & 0.0 \\
\hline Mar. & 0.0 & 2058.8 & 0.0 & 1938.0 & 1409.9 & 22.2 & 1491.1 & 17.3 \\
\hline Apr. & 0.0 & 2439.3 & 0.0 & 2323.8 & 573.0 & 328.3 & 630.6 & 289.7 \\
\hline May & 0.0 & 2931.0 & 0.0 & 2817.0 & 26.9 & 1362.0 & 33.2 & 1253.5 \\
\hline Jun. & 0.0 & 3058.0 & 0.0 & 2943.3 & 0.4 & 2008.8 & 0.5 & 1879.0 \\
\hline Jul. & 0.0 & 3311.5 & 0.0 & 3180.2 & 0.0 & 2626.3 & 0.0 & 2495.9 \\
\hline Aug. & 0.0 & 3279.1 & 0.0 & 3154.1 & 0.0 & 2042.9 & 0.0 & 1919.3 \\
\hline Sep. & 0.0 & 3138.0 & 0.0 & 3007.3 & 95.9 & 1050.2 & 104.6 & 970.7 \\
\hline Oct. & 0.0 & 2843.6 & 0.0 & 2719.0 & 421.9 & 90.3 & 453.4 & 76.1 \\
\hline Nov. & 0.0 & 2092.6 & 0.0 & 2005.6 & 2120.3 & 0.0 & 2159.9 & 0.0 \\
\hline Dec. & 0.0 & 1448.9 & 0.0 & 1372.5 & 4062.1 & 0.0 & 4092.3 & 0.0 \\
\hline Subtotal & 1.8 & 29569.6 & 2.1 & 28261.7 & 16473.4 & 9531.0 & 16843.5 & 8901.5 \\
\hline Total & \multicolumn{2}{|c|}{29571.4} & \multicolumn{2}{|c|}{28263.9} & \multicolumn{2}{|c|}{26004.5} & \multicolumn{2}{|c|}{25745.0} \\
\hline
\end{tabular}


Table 3

Cross-regional comparisons of HVAC energy performance of the control building

\begin{tabular}{l|cc|cc|cc|cc}
\hline Control Building & \multicolumn{2}{|c|}{ West } & \multicolumn{2}{c|}{ Midwest } & \multicolumn{3}{c|}{ South } & \multicolumn{2}{c}{ Northeast } \\
HVAC Performance & LA & SF & CHI & MN & MIA & HOU & BOS & NYC \\
\hline $\begin{array}{l}\text { Cooling Energy } \\
\text { Percentage (\%) }\end{array}$ & $\mathbf{9 9 . 4}$ & $\mathbf{9 3 . 3}$ & 46.8 & 36.7 & $\mathbf{9 9 . 9}$ & $\mathbf{9 6 . 9}$ & 49.4 & 61.6 \\
$\begin{array}{l}\text { Reduced Cooling } \\
\text { Energy (kWh) }\end{array}$ & $\mathbf{1 1 2 9 . 2}$ & 840.0 & 680.4 & 629.5 & $\mathbf{1 3 0 7 . 9}$ & $\mathbf{1 0 6 8 . 0}$ & 620.8 & 730.3 \\
$\begin{array}{l}\text { Reduced Cooling } \\
\text { Energy (\%) }\end{array}$ & $\mathbf{7 . 9}$ & $\mathbf{9 . 8}$ & 6.5 & 6.6 & 4.4 & 4.9 & $\mathbf{6 . 8}$ & 6.2 \\
$\begin{array}{l}\text { Reduced Total } \\
\text { Energy (kWh) }\end{array}$ & $\mathbf{1 1 1 0 . 3}$ & $\mathbf{7 5 2 . 8}$ & 370.4 & 259.5 & $\mathbf{1 3 0 7 . 5}$ & $\mathbf{1 0 0 1 . 2}$ & 302.1 & 457.0 \\
$\begin{array}{l}\text { Reduced Total } \\
\text { Energy (\%) }\end{array}$ & $\mathbf{7 . 7}$ & $\mathbf{8 . 2}$ & 1.7 & 1.0 & 4.4 & $\mathbf{4 . 4}$ & 1.6 & 2.4 \\
\hline
\end{tabular}



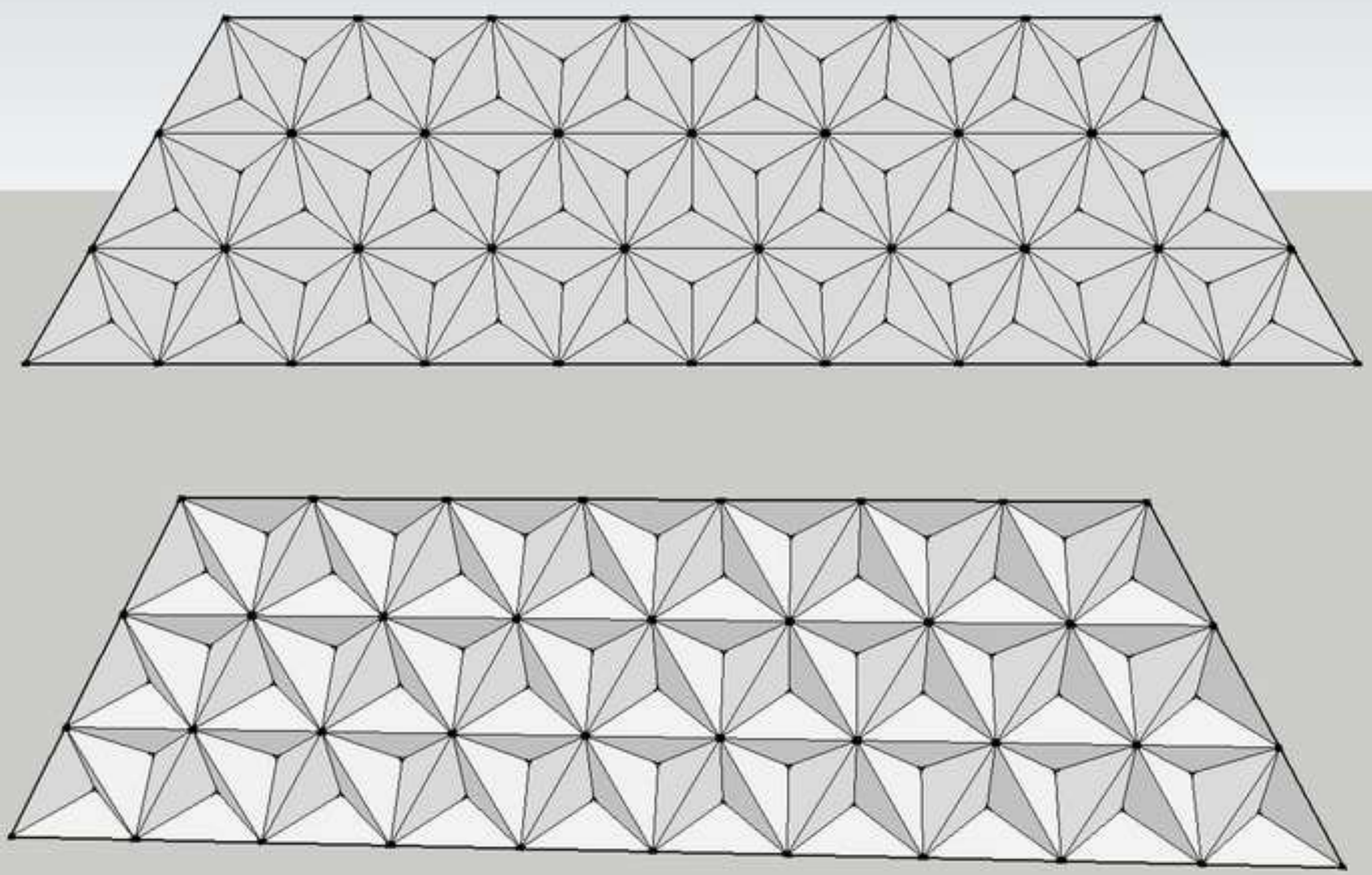


$$
1 \triangleq
$$



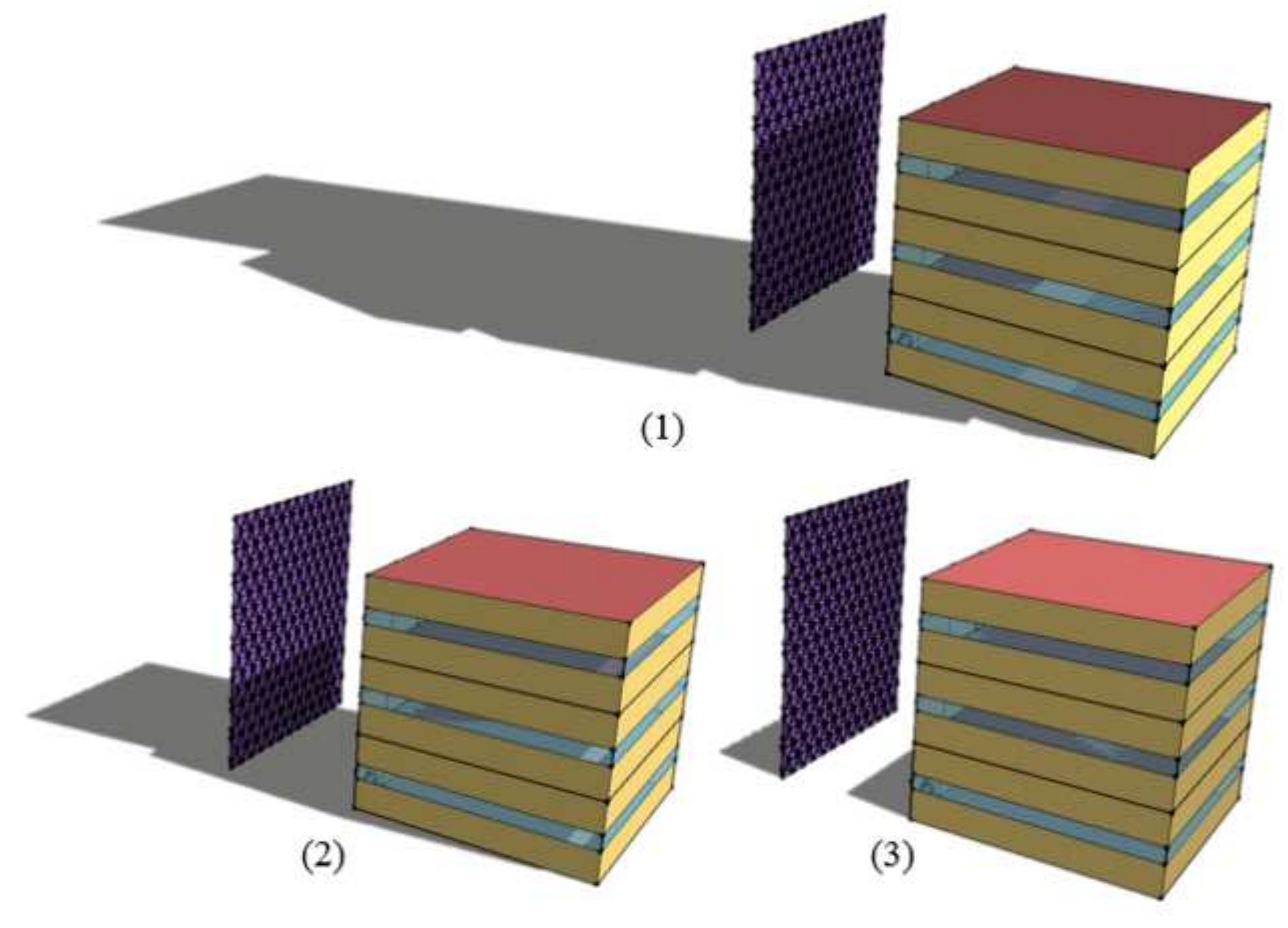

(1)

(2)

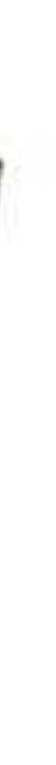


Figure 5
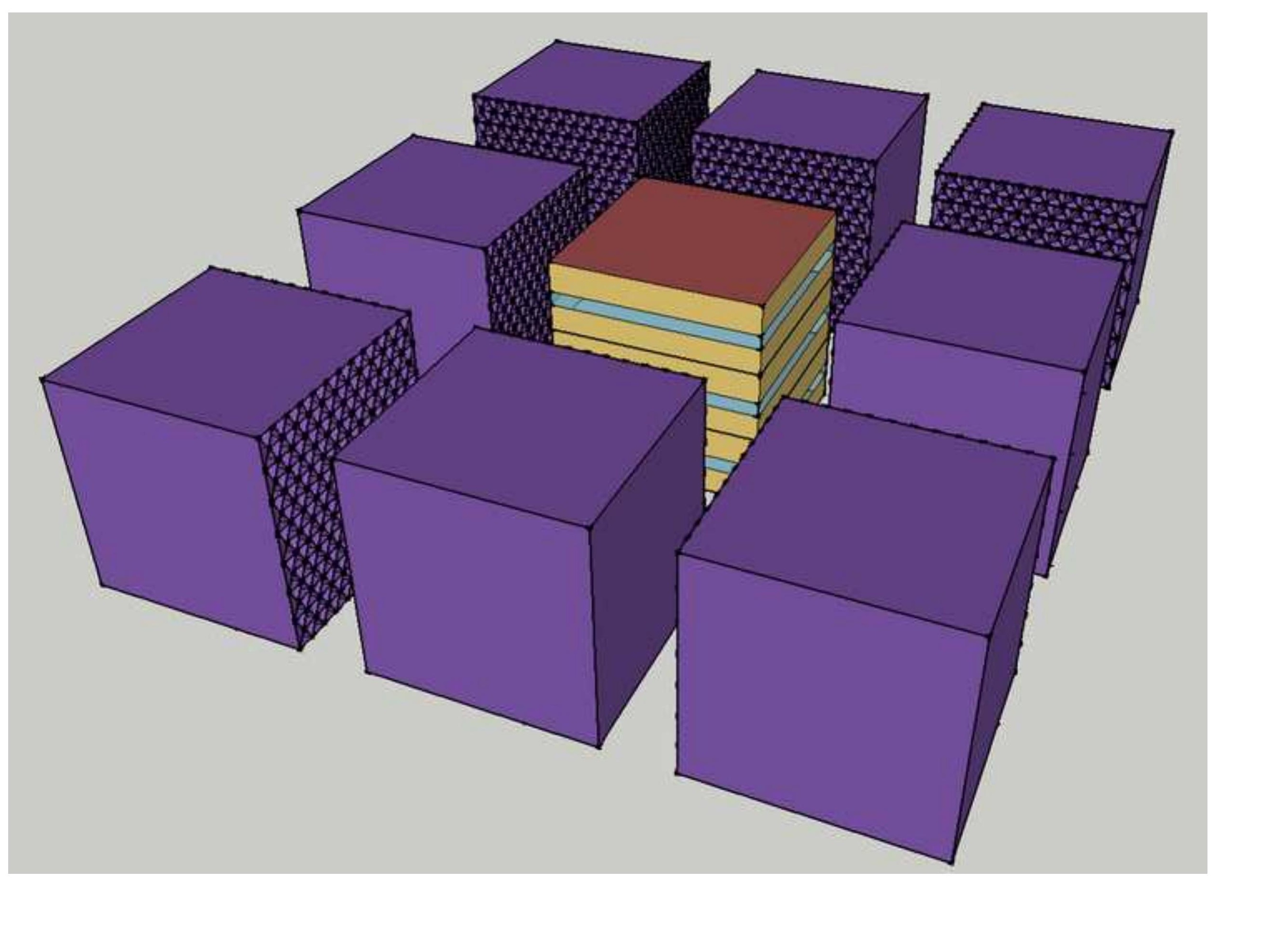


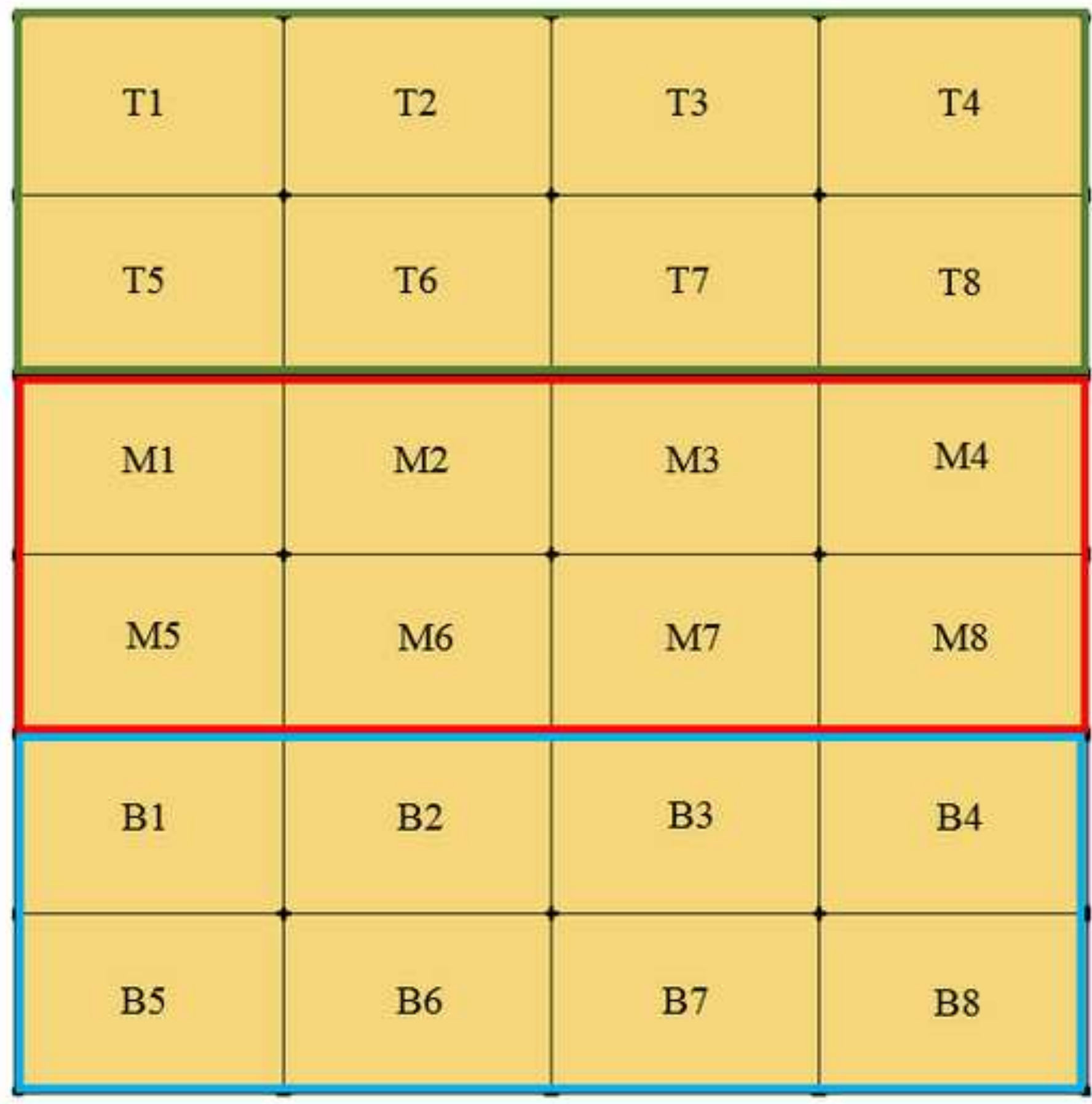

Top

Middle

Bottom

Bottom 
(1)

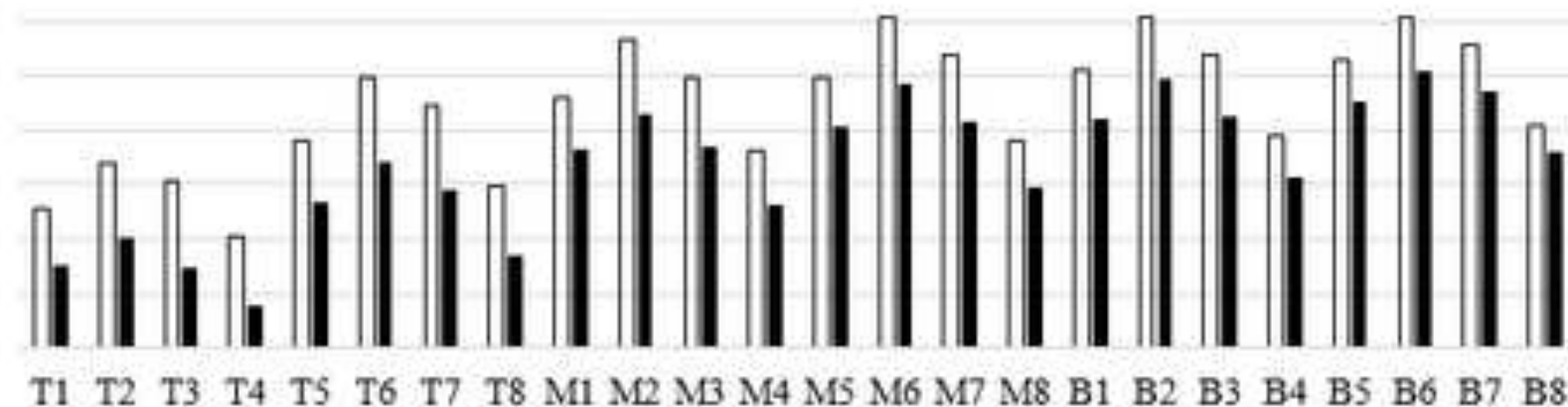
Position

(2)

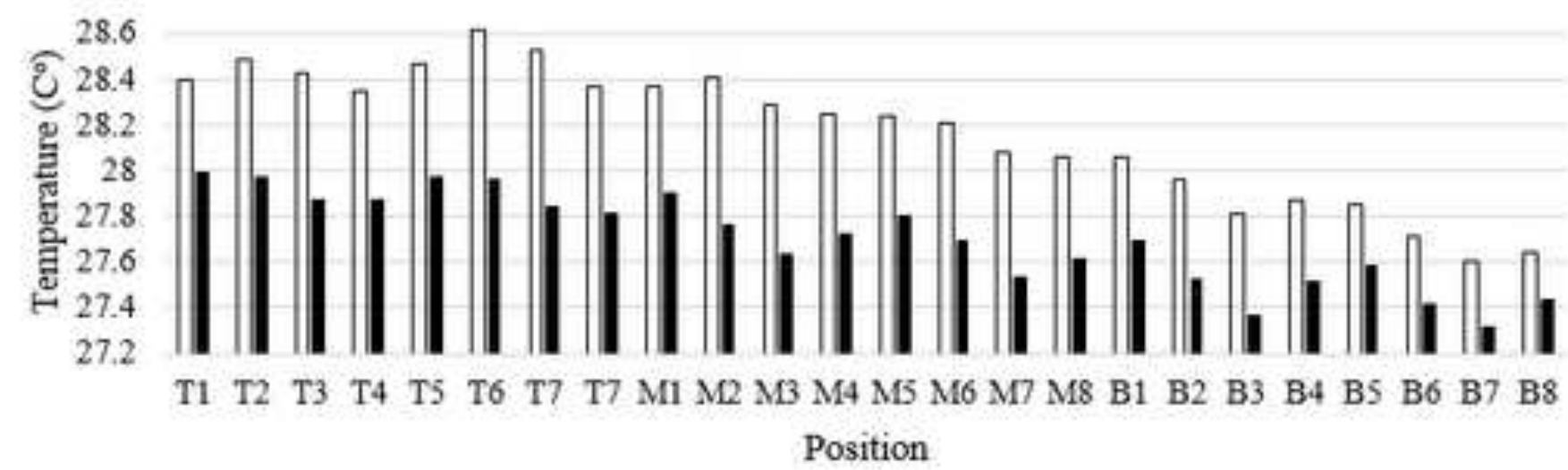

(3)

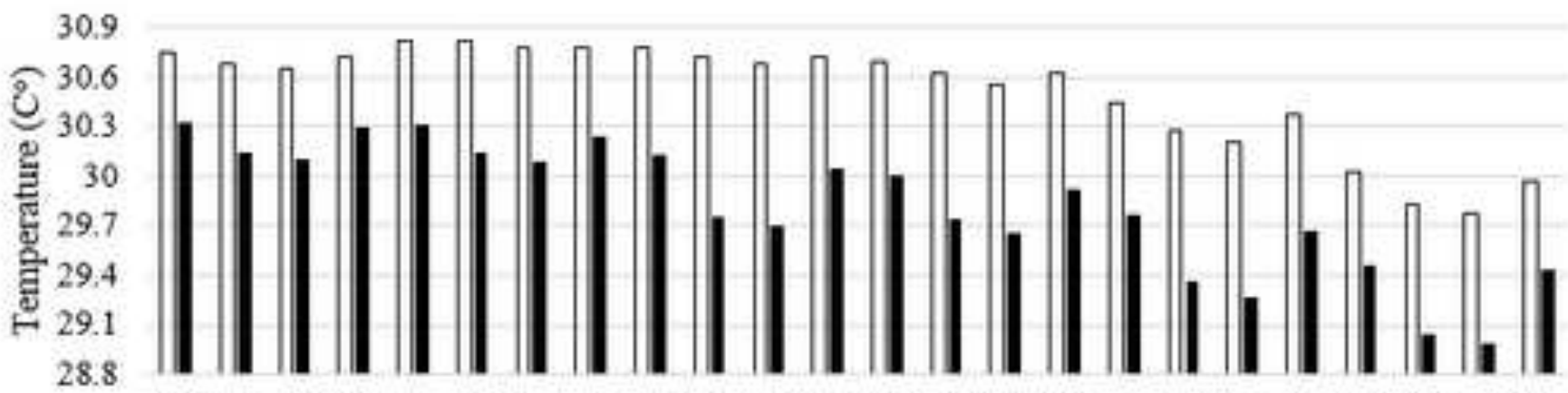

T1 T2 T3 T4 T5 T6 T7 T7 M1 M2 M3 M4 M5 M6 M7 M8 B1 B2 B3 B4 B5 B6 B7 Bs Position 

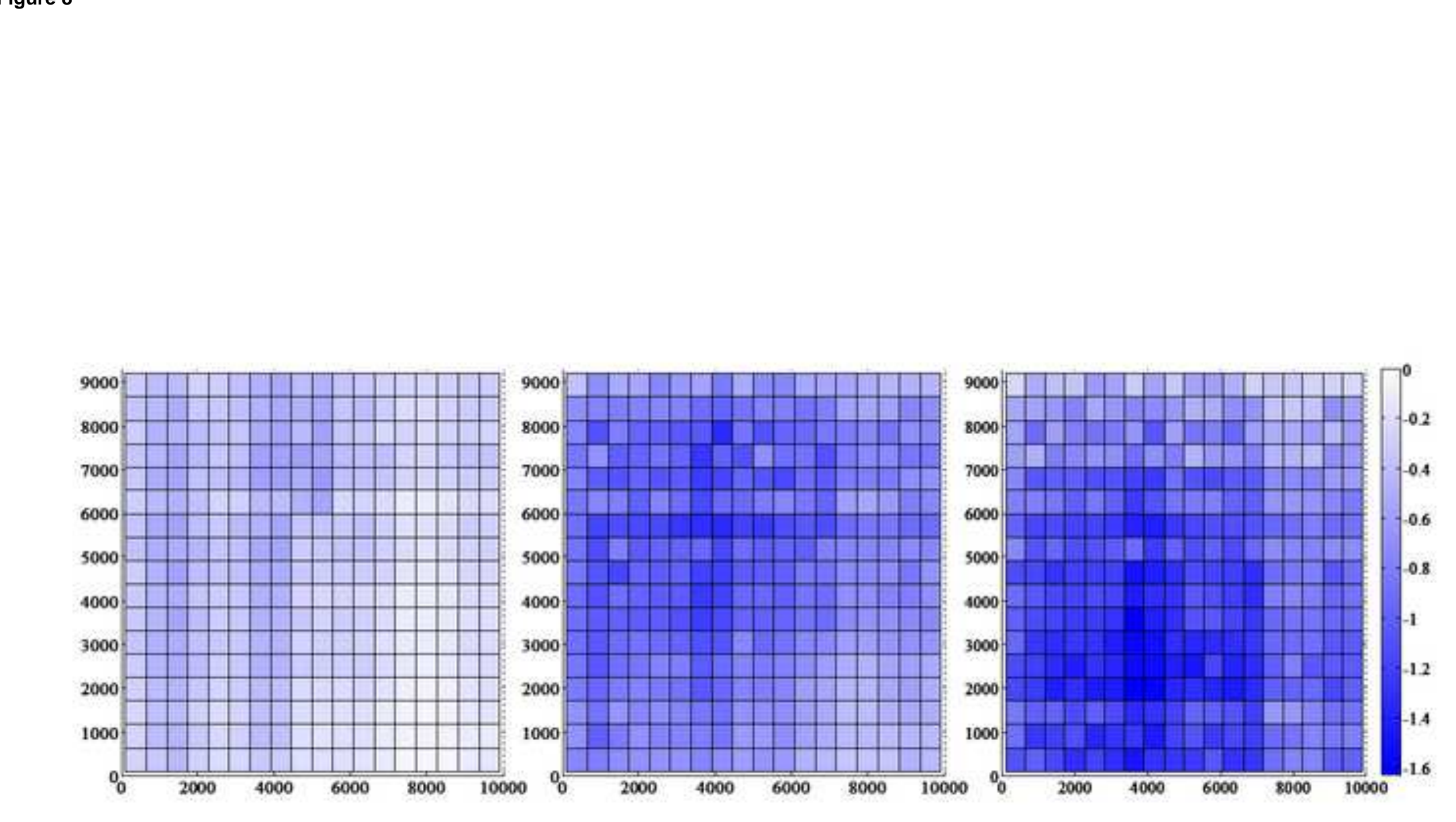

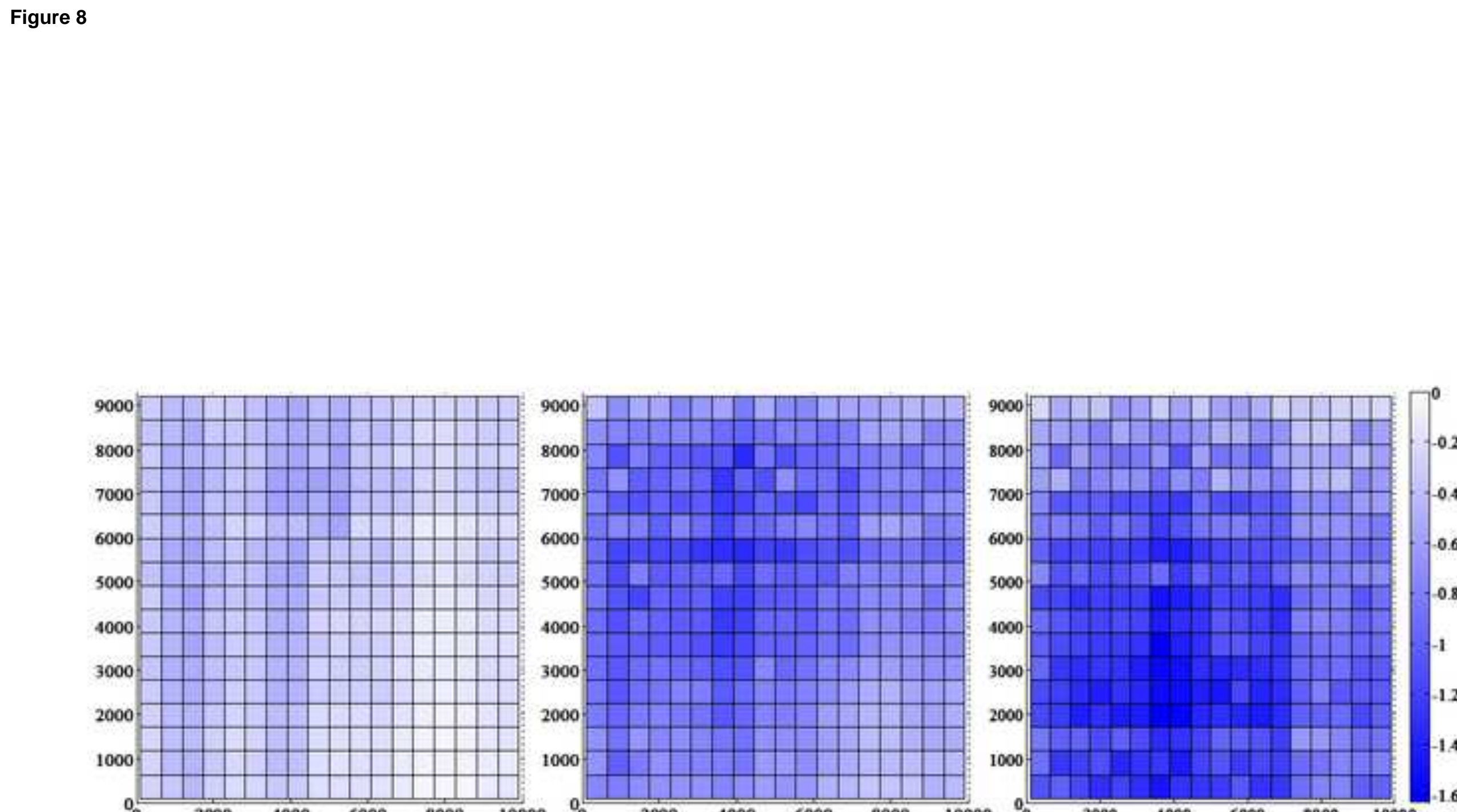

0.4

6

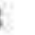

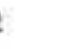

.

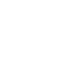




\section{List of Figure Captions}

Fig. 1. Retro-reflectant flower petals of Galanthus nivalis

Fig. 2. Macro-scale cubic-corner retroreflector array

Fig. 3. Case study 1: Reference building with testing surface

Fig. 4. Shading and reflection visualization at (1) 7 a.m., (2) 9 a.m., and (3) 11 a.m. in Case Study 1

Fig. 5. Case Study 2: A network of nine buildings with the control building in the middle of the block

Fig. 6. Control surface breakdown in Case Study 1

Fig. 7. Control surface temperature variations at (1) 7 a.m., (2) 9 a.m., and (3) 11 a.m. (Solid black histograms stand for when retro-reflective pattern diffusive wall was used for the testing surface; Black outlined histograms represent that a regular diffusive wall was used for the testing surface)

Fig. 8. Temperature difference distribution of the control building surface between diffusive and retroreflective testing façades 